\title{
Uso alternativo de lodo de estação de tratamento de água em pavimentação: uma revisão
}

Alternative use of water treatment plant sludge in paving: a review

Uso alternativo de lodos de plantas de tratamiento de agua en pavimentación: una revisión

Recebido: 12/05/2020 | Revisado: 29/05/2020 | Aceito: 29/05/2020 | Publicado: 14/06/2020

Ana Millene dos Santos Silva

ORCID: https://orcid.org/0000-0003-2110-8056 Instituto Federal de Educação, Ciência e Tecnologia do Ceará, Brasil E-mail: anasantosmillene@gmail.com

Eliezio Nascimento Barboza ORCID: https://orcid.org/0000-0001-8100-9389 Instituto Federal de Educação, Ciência e Tecnologia do Ceará, Brasil E-mail: eliezio1999@outlook.com

Maria Fernanda da Cruz Silva

ORCID: https://orcid.org/0000-0003-3346-6678 Instituto Federal de Educação, Ciência e Tecnologia do Ceará, Brasil E-mail: fernandacsilva56@gmail.com

\section{Resumo}

O rápido crescimento urbano e populacional aumentou a demanda por água potável. Consequentemente grandes quantidades de lodo são geradas nos decantadores das Estações de Tratamento de Água (ETA) como resultado do processo de tratamento. Esse resíduo, quando não descartado corretamente pode vir a ser um contaminante para o meio ambiente. $\mathrm{O}$ presente trabalho objetiva apresentar por meio de um estudo de revisão de literatura formas alternativas para a aplicação do lodo de ETA em pavimentação rodoviária com ênfase no agregado usado para estabilização e o processo de lixiviação, afim de avaliar uma destinação ambientalmente correta. Por meio da literatura estudada é possível concluir que o lodo pode ser aplicado nas camadas da pavimentação (base, sub-base e subleito), em concretos betuminosos e concretos para a recomposição de calçadas. No que se refere a estabilização, 
percebe-se o emprego de cimento, cal hidratada e solo. Quanto ao processo de lixiviação, verifica-se a maior presença de $\mathrm{Mn}, \mathrm{Fe}, \mathrm{Al}, \mathrm{Cd}, \mathrm{Pb}$ e $\mathrm{Ni}$ em vários estudos que contemplam esse teste.

Palavras-chave: Saneamento; Resíduos de ETA; Reutilização; Engenharia de Transporte.

\begin{abstract}
Rapid urban and population growth has increased demand for drinking water. Consequently, large amounts of sludge are generated in the decanters of the Water Treatment Plants (ETA) as a result of the treatment process. This residue, when not disposed of correctly, can become a contaminant to the environment. The present work aims to present through a literature review study alternative forms for the application of ETA sludge in road paving with emphasis on the aggregate used for stabilization and leaching process, in order to evaluate an environmentally correct destination. Through the literature studied it is possible to conclude that sludge can be applied in the paving layers (base, sub-base and subbed), in bituminous concrete and concrete for the recomposition of sidewalks. With regard to stabilization, the use of cement, hydrated lime and soil is perceived. Regarding the leaching process, there is a greater presence of $\mathrm{Mn}, \mathrm{Fe}, \mathrm{Al}, \mathrm{Cd}, \mathrm{Pb}$ and $\mathrm{Ni}$ in several studies that contemplate this test.
\end{abstract}

Keywords: Sanitation; WTS waste; Reuse; Transportation Engineering.

\title{
Resumen
}

El rápido crecimiento urbano y poblacional ha aumentado la demanda de agua potable. En consecuencia, se generan grandes cantidades de lodos en los decantadores de las Plantas de Tratamiento de Aguas (ETA) como resultado del proceso de tratamiento. Este residuo, cuando no se elimina correctamente, puede convertirse en un contaminante para el medio ambiente. El presente trabajo tiene como objetivo presentar a través de un estudio de revisión de la literatura formas alternativas para la aplicación de lodos ETA en la pavimentación de carreteras con énfasis en el agregado utilizado para el proceso de estabilización y lixiviación, con el fin de evaluar un destino ambientalmente correcto. A través de la literatura estudiada es posible concluir que los lodos se pueden aplicar en las capas de pavimentación (base, subbase y subbed), en hormigón bituminoso y hormigón para la recomposición de las aceras. Con respecto a la estabilización, se percibe el uso de cemento, cal hidratada y suelo. En cuanto al proceso de lixiviación, hay una mayor presencia de $\mathrm{Mn}, \mathrm{Fe}, \mathrm{Al}, \mathrm{Cd}, \mathrm{Pb}$ y $\mathrm{Ni}$ en varios estudios que contemplan esta prueba.

Palabras clave: Saneamiento; Residuos de ETA; Ingeniería de reutilización y transporte. 


\section{Introdução}

Com a intensa urbanização nos últimos séculos, especialmente no século XXI, nota-se a necessidade de melhorias na qualidade de vida para a população, principalmente no que se refere a salubridade ambiental por meio do saneamento básico. O crescimento caótico sem o devido planejamento dos núcleos urbanos, através da ocupação de áreas irregulares e sem infraestrutura, causou diversos problemas socioeconômicos e ambientais (Rangel, 2005). Neste contexto, destacam-se as questões de saneamento ambiental e saúde pública, intimamente ligada ao aumento na demanda por água potável e consequentemente na quantidade de resíduo gerado nas Estações de Tratamento de Água - ETA (Ribeiro \& Rooke, 2010).

Para o fornecimento de água de abastecimento nos padrões de potabilidade estabelecidos pelas legislações vigentes, uma série operações e processos unitários de tratamento são realizados nas ETA visando garantir sua potabilidade, como: coagulação, floculação, decantação, filtragem e desinfecção (Achon, Barroso \& Cordeiro, 2013).

No processo de floculação, caracterizado como a fase de mistura lenta pela adição e dispersão do coagulante para aglutinar as partículas de impurezas presente na água (geralmente o sulfato de alumínio - $\left.\mathrm{Al}_{2}\left(\mathrm{SO}_{4}\right)_{3}\right)$ por mistura rápida, no qual a principal finalidade é acelerar a colisão das partículas formando a aglomeração de partículas coloidais, os chamados flocos de ETA (Kawamura, 2000), que posteriormente serão sedimentados. O material decantado é chamado de resíduo de ETA (lodo de ETA), característica intrínseca do tratamento. O lodo de ETA é um resíduo não biodegradável rico em minerais de silicatos e matéria orgânica, acrescentados de produtos resultantes dos reagentes químicos que são aplicados durantes os processos unitários (Rodrigues \& Holanda, 2013).

A disposição final ambientalmente correta do lodo de ETA é um problema emergente para a sociedade, tendo em vista que quando dispostos em cursos de água sem tratamento adequado, esse material representa uma fonte potencial de riscos ao meio ambiente e a saúde humana pela sua alta toxicidade (Andreoli \& Pinto, 2001). O lodo da ETA é caracterizado como resíduo sólido, e proibido em termos legais de ser lançado em praias, mar ou em corpos hídricos, pelo risco de contaminação tanto dos corpos aquáticos e animais que habitam esse ecossistema, quanto para população, pratica essa, muito adotada anteriormente a essa legislação (NBR, 2004).

O destino final do lodo provenientes das estações de tratamento é vista como uma atividade de grande importância e complexidade no mundo inteiro, já que normalmente 
extrapola os limites das estações de tratamento e exige a integração com outros setores da sociedade (Andreoli \& Pinto, 2001). Atualmente fala-se em soluções ambientalmente corretas para destinação final desse resíduo. A maior questão é de que forma ele poderá ser empregado com o menor custo possível como alternativa quem não venha a causar danos ao meio ambiente pela degradação do solo ou da água, representando assim, uma problemática a ser solucionada. Os lodos gerados nas Estações de Tratamento de Água por serem classificados como resíduos sólidos, é necessário serem tratados e dispostos no meio ambiente e seu reuso deve ser devidamente desidratado em cerca de $65 \%$, podendo ser destinado para adubação, incineração, aterro sanitários e compostagem com lixo urbano (Teixeira, Souza, Souza, Aléssio \& Santos, 2006).

Além das utilidades do lodo citadas anteriormente, diversos estudos afirmam que o lodo da ETA pode ser utilizado na construção civil como aditivo para agregados na pavimentação (Hoppen, Portella, Joukoski, Trindade \& Andreóli, 2006; Silva, 2008; Costa, 2011; Pereira, 2012; Martinez, 2014; Lucena, Thomé Juca, Soares \& Portela, 2014; Coelho, Tahira, Fernandes, Fontenele \& Teixeira, 2015; Delgado, 2016; Fernandez \& Mikowski, 2016; Alves, 2019; Klein \& Oliveira, 2019). Godoi (2013) afirma que o lodo pode ser utilizado em pavimentação de vias aplicando os resíduos provenientes do tratamento de água e esgoto, reduzindo gastos e amenizando possíveis impactos ambientais.

Sendo a pavimentação rodoviária uma obra em crescente desenvolvimento e de grande influência na economia do Brasil (Pereira \& Lessa, 2011) e o lodo de ETA com ótimas propriedades para ser utilizado na pavimentação rodoviária, contribuindo essencialmente na redução de impactos negativos ao meio ambiente, o presente trabalho objetiva a partir de um estudo de revisão de literatura, analisar o uso do lodo de ETA em pavimentação rodoviária mostrando as principais formas de aplicação desse resíduo. Com ênfase na comparação dos parâmetros do tipo de agregado usado; em segundo plano: o processo de lixiviação e presença de metais pesados. 


\section{Metodologia}

\subsection{Tipo de pesquisa}

Conforme caracterizam Pereira et al. (2018), do ponto de vista da natureza, esse trabalho trata-se de uma pesquisa básica. Pelas perspectivas de abordagem, é uma pesquisa qualitativa. Analisando os objetivos essa pesquisa é exploratória. Em relação aos procedimentos técnicos é do tipo revisão bibliográfica.

\subsection{Realização do estudo}

O presente artigo de revisão baseou-se em trabalhos da base de dados de literatura científica Google Acadêmico, utilizando-se as publicações de janeiro de 2000 a janeiro de 2020, tendo as seguintes palavras-chave: Lodo, ETA, Lodo de ETA e uso do lodo de ETA. Os dados foram obtidos por meio de publicações em revistas, Trabalhos de Conclusão de Curso, dissertações de mestrado e doutorado. Além das publicações na base de dados Google Acadêmico, foi utilizado nesse estudo as Normas: DNIT 143/2010 - ES, DNER-ME 201/94, NBR 10004, NBR 10005; as Portarias: $n^{\circ} 2.914$, de dezembro de 2011 e Portaria $\mathrm{n}^{\circ} 518$, de 25 de março de 2004; e a Lei n $^{\circ}$ 12.305, de 2 de agosto 2010 que institui a Política Nacional de Resíduos Sólidos - PNRS.

Para organizar as informações dos artigos selecionados da base dados, contidas em 11 publicações, foi utilizada a leitura flutuante dos títulos e resumos dos trabalhos bem como os resultados apresentados. A métrica utilizada para a seleção das literaturas foi a aplicação direta do lodo de estação de tratamento em pavimentação rodoviária de forma alternativa, com ênfase nas publicações que abordam o tipo de agregado usado em testes mecânicos e o processo de lixiviação. Os dados foram registrados em forma de tabela para os principais agregados apresentados nos estudos, e suas aplicações na pavimentação rodoviária são abordadas junto com as especificações dos testes feitos pelos autores. O processo de lixiviação foi registrado de forma secundária, para as literaturas que apresentavam esse parâmetro. 


\subsection{Critérios de amostragem utilizados}

Critérios de inclusão: estudos encontrados no banco de dados de literatura científica Google Acadêmico, publicados no período de janeiro de 2000 a janeiro de 2020, utilizando as palavras-chave: Lodo, ETA, Lodo de ETA e uso do lodo de ETA, além das consultas específicas das Normas: DNIT 143/2010 - ES, DNER-ME 201/94, NBR 10004, NBR 10005; as Portarias: $\mathrm{n}^{\circ}$ 2.914, de dezembro de 2011 e Portaria $\mathrm{n}^{\circ}$ 518, de 25 de março de 2004; e a Lei $\mathrm{n}^{\mathrm{o}}$ 12.305, de 2 de agosto 2010 que institui a Política Nacional de Resíduos Sólidos PNRS.

Critérios de exclusão: artigos publicados fora do período de janeiro de 2000 a janeiro de 2020 e artigos que não abordavam o tema de interesse no presente artigo.

\section{Resultados e Discussão}

\subsection{Caracterização da literatura abordada}

Após a filtragem das publicações, foram selecionadas 11 literaturas abordando o uso de lodo de estação de tratamento de água em pavimentação rodoviária e lixiviação, sendo 5 dissertações de mestrado, 3 artigos científicos, 2 dissertações de doutorado e 1 trabalho de conclusão de curso. Importante ressaltar a pouca quantidade de trabalhos publicados sobre o assunto, possivelmente pela recente preocupação com resíduo gerado nas ETA. O Quadro 1 apresenta a caracterização da literatura em vista aos parâmetros estabelecidos.

Quadro 1: Caracterização da literatura em vista aos parâmetros estabelecidos.

\begin{tabular}{|l|c|}
\hline \multicolumn{1}{|c|}{ Parâmetros abordados } & $\mathrm{N}^{\circ}$ de literaturas \\
\hline $\begin{array}{l}\text { Apresenta abordagem quanto ao agregado usada } \\
\text { e sua aplicação na pavimentação, sem } \\
\text { abordagem sobre lixiviação. }\end{array}$ & 3 \\
\hline $\begin{array}{l}\text { Apresenta abordagem direta quanto ao agregado, } \\
\text { a aplicação e o processo de lixiviação. }\end{array}$ & 3 \\
\hline $\begin{array}{l}\text { Apresenta abordagem sobre aplicação e } \\
\text { lixiviação. }\end{array}$ & 2 \\
\hline $\begin{array}{l}\text { Apresenta abordagem geral sobre aplicação sem } \\
\text { especificar o agregado usado, ou o processo de } \\
\text { lixiviação. }\end{array}$ & 3 \\
\hline
\end{tabular}

Fonte: Autores, 2020. 
O Quadro 1 apresenta a caracterização dos trabalhos abordados nesse estudo, de acordo com o conteúdo abordado, mostrando a distinção das pesquisas quanto aos parâmetros estabelecidos.

\subsection{Tratamento de água e uso alternativo do lodo}

A demanda por água de qualidade tem aumentado constantemente nas últimas décadas em decorrência do desenvolvimento urbano e crescimento populacional mundial, como esclarece Brasil (2011), a disponibilidade dos recursos hídricos envolve as questões de qualidade da água, que por sua vez é afetada pela poluição das suas fontes, como mananciais subterrâneos e artificias, onde um dos fatores é o aumento no despejo de esgotos não tratados. Por consequência, a qualidade da água é degradada tornando-se escassa e aumentando também a demanda por tratamentos que garanta a água própria para consumo humano.

Segundo Brasil (2011), entende-se por água tratada aquela submetida a processos físicos, químicos ou ambos, que tenha como objetivo atender ao padrão de potabilidade, estabelecidos na Portaria $n^{\circ}$ 2.914, de 12 de dezembro de 2011, no qual dispõe sobre os procedimentos de controle e de vigilância da qualidade da água para consumo humano e seu padrão de potabilidade, onde é considerado água potável aquela que não ofereça riscos à saúde humana. Monteiro (2014) complementa ao afirmar que sistema de abastecimento de água é o processo de transformação da água bruta em água potável, disponível para o consumo humano. Assim, esse processo consiste em uma série de etapas realizadas nas estações de tratamento de água, para garantir sua qualidade.

O tratamento de água convencional envolve algumas etapas (coagulação, floculação, decantação, filtração, desinfecção e fluoretação). Nesse contexto, como resultado do processo realizado nas fases de coagulação e floculação, pela ação de produtos químicos, ocorre à formação de sedimentos (lodo de ETA), gerados a partir das partículas da água bruta, que geralmente são removidos, armazenados e posteriormente despejados em cursos de água próximos a estação (Andreoli \& Pinto, 2001).

Só a Companhia de Saneamento Básico do Estado de São Paulo - SABESP é responsável por mais de 200 ETA, onde cerca de 120 mil litros de água são tratados por segundo (SABESP, 2019). Iwaki (2018) corrobora ao afirmar que esse grande volume de água tratada representa aproximadamente 90 toneladas de lodo em base seca produzido por dia, nos municípios operados pela SABESP, enfatizando uma variação nos períodos chuvosos 
onde os parâmetros de cor aparente e turbidez tende a piorar, demandando maiores quantidades de coagulantes a serem aplicados.

A NBR (2004) classifica os lodos produzidos nas estações de tratamento de água como resíduos sólidos que possuem impacto a saúde e ao meio ambiente, para os quais é necessário dar uma destinação adequada. Em consonância, Brasil (2010) define como destinação final ambientalmente adequada aquela que inclui atos como reutilização e aproveitamento energético. O Art. 47 da Lei no 12.305 (2010), que institui a Política Nacional de Resíduos Sólidos, trata ainda das proibições quando a destinação final desses resíduos, como o seu lançamento corpos hídricos.

Ainda segundo a NBR (2004), o lançamento dos resíduos gerados nas ETA na rede pública de esgoto ou corpos aquáticos demandam soluções técnicas e econômicas inviáveis atualmente. Diante disso, soluções alternativas são buscadas para minimizar os danos causados pelo lodo ao meio ambiente. Hoppen, Portella, Joukoski, Trindade e Andreóli (2006) mostram em seus estudos que o lodo proveniente do processo de tratamento de água pode ser empregado em matriz de concreto Portland. Os autores observaram que a adição desse resíduo reduz o consumo de outros insumos, como cimento e agregados, o que demostra vantagens do ponto de vista tanto econômico, quanto ambiental pela redução de matérias extraídos da natureza e o emprego alternativo do lodo.

Como explica Wolff (2008), o uso de resíduos de ETA juntamente com materiais derivados da indústria de celulose e pó de granito, também pode ser usado na produção de cerâmica vermelha. Para o autor, o lodo seco pode ser usado juntamente com outros materiais desplastificantes na fabricação de cerâmica vermelha, e empregado na construção de revestimentos de uso interno ou material acústico. No mesmo sentido, o resíduo ainda pode ser empregado em material cerâmico estrutural, dependendo da temperatura de queima, o lodo pode ser usado na produção de tijolos respeitando as propriedades tecnológicas na fabricação desse material (Teixeira, Souza, Souza, Aléssio \& Santos, 2006).

Diante disso, o lodo de ETA pode também ser empregado na construção de pavimentos rodoviários, pois como explica Delgado (2016), o pavimento é uma obra linear, sendo uma estrutura de múltiplas camadas assentes sobre uma fundação chamada subleito, a maioria das camadas são constituídas por materiais de origem natural, com características marcantes, variando de acordo com a qualidade do material do subleito. Segundo o autor, em um pavimento a estrutura está formada por camadas, colocadas sobre o subleito: a sub-base, a base e o revestimento, nominadas na ordem ascendente de posição vertical. Materiais naturais 
são necessários, pois necessitam de grandes quantidades de matérias primas para abastecer os quilômetros a serem feitos.

A adição de lodo pode melhorar a qualidade do solo e o seu desempenho pela técnica de estabilização. Como explica Coelho, Tahira, Fernandes, Fontenele \& Teixeira (2015), a estabilização do solo é uma técnica usada visando melhorias quanto a sua aplicação em processos construtivos, podendo ser mecânica, granulométrica e com aditivos.

\subsection{Aplicações do lodo de Estação de Tratamento em pavimentação rodoviária}

A aplicação do lodo de ETA na pavimentação segue um leque de vias. No trabalho de Martinez (2014) o lodo é empregado em misturas betuminosas afim de avaliar o desempenho do concreto asfáltico. A pesquisa demostrou que é viável a utilização do resíduo calcinado, com melhores resultados para o Lodo em $500^{\circ}$ de calcinação e aplicação em concretos betuminosos.

Como abordado por Geyer (2001), o método de incineração do lodo é válido para a redução do seu volume e proporciona melhores condições para a sua disposição, além de possuir grande potencial de aproveitamento como subproduto em obras. Nesse caso, permitindo após estabilização, o descarte seguro desse resíduo na indústria de pavimentação. O tipo de agregado usado juntamente com o lodo para a estabilização da construção rodoviária é primordial para atender as propriedades físicas, químicas e mineralógicas dos materiais convencionalmente usados.

Nos estudos de Lucena, Thomé Juca, Soares \& Portela (2014) usando cal, cimento e emulsão como estabilizantes com teores variando de $2,4,6,8 \%$ e $10 \%$ do lodo de estação de tratamento, após testes de força, foi possível verificar o potencial das misturas para a utilização em base e sub base de pavimentação de rodovias. Este estudo mostra que $8 \%$ de cimento usado como aditivo apresenta os melhores resultados para resistência, com 1500 kpa para compressão simples e 0,364 Mpa para tração, ambos com cura a seco em 7 dias.

No Brasil o Departamento Nacional de infraestruturas de transportes (DNIT) especifica que misturas do tipo solo-cimento devem apresentar valor mínimo de 2,1 Mpa para resistência a compressão aos 7 dias (DNIT 143, 2010) quanto as especificações de ensaio (DNER-ME 201, 1994).

O lodo de ETA pode ser empregado junto com solo argiloso e solo arenoso na camada de subleito, bem como a mistura de solo arenoso com $10 \%$ de cimento, possui caráter apropriado para o uso em base de pavimentação, no qual foram testadas as misturas de dois 
solos de granulometrias diferentes (arenosos e argiloso) e lodo, nas proporções de 1:1 do solo argiloso + lodo com adição de 6 e 10\% de cimento; e para o solo arenoso 1:0,25 sem adição de cimento (Coelho, Tahira, Fernandes, Fontenele \& Teixeira, 2015).

Para os resultados acima, os autores apontam que a mistura do tipo solo argiloso + lodo com adição de cimento atingiu apenas 0,27 Mpa para resistência a compressão em 7 dias (média), a qual não atende os requisitos da norma (DNIT 143, 2010) para uso em base de pavimentação; em contrapartida o solo arenosos+ lodo com adição de $10 \%$ de cimento atende a norma com uma média de 2,7 Mpa para o mesmo teste. Todas as outras misturas com os dois solos foram aprovadas para a camada de subleito.

Em consonância com Lucena, Thomé Juca, Soares \& Portela (2014), é possível verificar uma dificuldade de melhor estabilização para atingir resultados favoráveis nos testes de compressão nas misturas estudadas, para que atinjam maiores resistência. Tratando do uso alternativo do lodo de ETA, Costa (2011) levanta uma abordagem sobre a estabilização de concreto para a recomposição de calçadas.

O autor realiza estudos para avaliar o uso do lodo em 5, 10 e $20 \%$ como agregado miúdo juntamente com areia, para o concreto convencionalmente aplicado na construção de calçadas (Cimento, areia e brita; 1:2,3). Assim, o estudo mostra que em todas as misturas a resistência a compressão axial são superiores a $15 \mathrm{Mpa}$, e os resultados para tração têm melhores valores com $10 \%$ de lodo sendo aplicado na mistura.

Estudo semelhante desenvolvido por Hoppen, Portella, Joukoski, Trindade \& Andreóli (2006) utilizando lodo aplicado ao concreto mostrou que 8\% de lodo de ETA atingiu uma resistência a compressão de 21,45 Mpa em 7 dias; sendo que segundo os autores, o limite de $10 \%$ deve ser considerado, uma vez que a resistência cai significativamente para cerca de $15 \mathrm{Mpa}$, semelhante ao estudo anteriormente citado, mostrando uma aplicação pratica em concretos não estruturais, como pavimentos e calçadas. Dessa forma, reduzindo o uso de outros insumos, como cimento, brita e areia.

Segundo Delgado (2016), outra maneira de aplicabilidade para o resíduo de ETA é o seu emprego na camada de sub-base de pavimentação rodoviária. A autora deteve seu trabalho ao estudo do comportamento do lodo quando feitas as misturas com pó de pedra, solo arenoso e solo argiloso para as porcentagens de 5, 10 e 15\% do resíduo.

Os melhores resultados para as propriedades mecânicas estão no uso do pó de pedra + $5 \%$ de lodo sem a adição de estabilizantes, e quando empregado o maior valor para lodo (15\%) essa mesma mistura obteve resultados satisfatórios com $2 \%$ de cimento na estabilização; demostrando grande potência de uso para rodovias de baixo volume de trafego. 
Neste contexto, uma nova abordagem pode ser levada em consideração para o destino do Resíduo de Serragem da Pedra Cariri (RSPC), muito explorada na região do Cariri Cearense, aplicado na construção de pavimentos.

O Quadro 2 apresenta os principais estudos encontrados sobre o uso de lodo de ETA em pavimentação rodoviária.

Quadro 2: Principais estudos sobre uso de lodo de ETA em pavimentação.

\begin{tabular}{|c|c|c|c|}
\hline Agregado & $\begin{array}{c}\text { Melhores valores } \\
\text { testados }\end{array}$ & $\begin{array}{c}\text { Uso na } \\
\text { pavimentação }\end{array}$ & Referência \\
\hline $\begin{array}{l}\text { Solo, } \\
\text { cimento, emulsão. }\end{array}$ & $\begin{array}{l}8 \% \text { de cimento e } 10 \% \text { de } \\
\text { lodo confere maiores } \\
\text { resistências }\end{array}$ & $\begin{array}{l}\text { Base e Sub-base } \\
\text { de pavimentação }\end{array}$ & $\begin{array}{l}\text { Lucena, Thomé Juca, } \\
\text { Soares e Portela (2014) }\end{array}$ \\
\hline $\begin{array}{l}\text { Concreto } \\
\text { convencional } \\
\text { (cimento, areia e } \\
\text { brita } 1: 2: 3 \text { ) }\end{array}$ & $\begin{array}{l}10 \% \text { de lodo coagulado } \\
\text { com cloreto de } \\
\text { polialumínio }\end{array}$ & $\begin{array}{l}\text { Recomposição } \\
\text { de calçadas }\end{array}$ & Costa (2011) \\
\hline $\begin{array}{l}\text { Concreto } \\
\text { betuminoso com } \\
\text { adição de lodo } \\
\text { calcinado }\end{array}$ & $\begin{array}{l}\text { Lodo em } \quad 500^{\circ} \mathrm{C} \\
\text { calcinação }\end{array}$ & $\begin{array}{l}\text { Concreto } \\
\text { betuminoso } \\
\text { usinado a quente }\end{array}$ & Martinez (2014) \\
\hline $\begin{array}{l}\text { Solo argiloso e } \\
\text { Solo arenoso+ } \\
\text { cimento }\end{array}$ & $\begin{array}{l}\text { Solo arenoso e argiloso; } \\
\text { Solo arenoso+ } 10 \% \text { de } \\
\text { cimento }\end{array}$ & $\begin{array}{l}\text { Subleito; Base } \\
\text { de pavimentação }\end{array}$ & $\begin{array}{l}\text { Coelho, Tahira, } \\
\text { Fernandes, Fontenele e } \\
\text { Teixeira (2015). }\end{array}$ \\
\hline $\begin{array}{l}\text { Solo+ pó de pedra } \\
+ \text { cimento }\end{array}$ & $\begin{array}{l}5 \% \text { de lodo + pó de } \\
\text { pedra; } 15 \% \text { de lodo }+2 \% \\
\text { de cimento }\end{array}$ & $\begin{array}{l}\text { Sub-base de } \\
\text { pavimentação }\end{array}$ & Delgado (2016) \\
\hline $\begin{array}{l}\text { Concreto } \\
\text { convencional }\end{array}$ & $\begin{array}{l}4 \text { e } 8 \% \text { de Lodo em } \\
\text { matriz de concreto }\end{array}$ & $\begin{array}{lr}\text { Pisos } & \text { e } \\
\text { construção } & \text { de } \\
\text { calçadas } & \end{array}$ & $\begin{array}{l}\text { Hoppen, Portella, } \\
\text { Joukoski, Trindade e } \\
\text { Andreóli (2006) }\end{array}$ \\
\hline $\begin{array}{l}\text { Concreto } \\
\text { betuminoso }\end{array}$ & 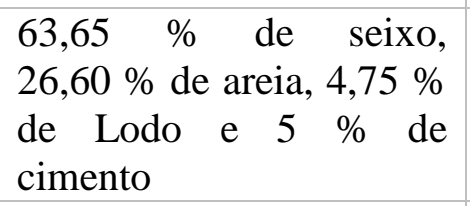 & $\begin{array}{l}\text { Concreto } \\
\text { betuminoso } \\
\text { usinado a quente }\end{array}$ & Silva (2008) \\
\hline $\begin{array}{l}\text { Concreto }+2,5 \\
5,0 \text { e } 7,5 \% \text { de } \\
\text { lodo }\end{array}$ & $\begin{array}{l}5,0 \% \text { de lodo em relação } \\
\text { a massa de cimento }\end{array}$ & $\begin{array}{l}\text { Concreto para } \\
\text { pavimentação } \\
\text { intertravada }\end{array}$ & $\begin{array}{l}\text { Fernandez e Mikowski } \\
\text { (2016) }\end{array}$ \\
\hline $\begin{array}{l}\text { Lodo puro; Cal } \\
\text { hidratada r e } \\
\text { Cimento Portland }\end{array}$ & $\begin{array}{l}9 \% \text { de Cimento; } 9 \text { e } 13 \% \\
\text { de Cal para MR }\end{array}$ & $\begin{array}{l}\text { Subleito e Sub- } \\
\text { base de } \\
\text { pavimentação }\end{array}$ & Alves (2019) \\
\hline $\begin{array}{l}\text { Cimento+ cinza } \\
\text { de lodo }\end{array}$ & $\begin{array}{l}71 \% \text { de solo+ } 9 \% \text { de } \\
\text { cimento }+20 \% \text { de cinzas }\end{array}$ & $\begin{array}{l}\text { Base e Sub base } \\
\text { de pavimentação }\end{array}$ & Pereira (2012) \\
\hline Não Especificado & Não especificado & $\begin{array}{l}\text { Sub-base de } \\
\text { pavimentos }\end{array}$ & Klein e oliveira (2019) \\
\hline
\end{tabular}

Fonte: Organizado pelos autores, 2020. 
O Quadro 2 apresenta os estudos de interesse nesse artigo, como também o tipo de agregado, os melhores valores testados (em porcentagem) e o uso na pavimentação (subleito, sub-base e base).

\subsection{O processo de lixiviação}

Como definido pela ABNT (2004) a lixiviação pode ser entendida como o processo para determinar a capacidade de transferência de substancias orgânicas e inorgânicas contidas em resíduos sólidos, por meio da sua dissolução no meio exterior.

A lixiviação é um processo muito importante para o estudo do uso de lodo de ETA em pavimentação, para que não venha a ocorrer a contaminação do solo ou da água quando dispostos na construção.

Dessa forma, nos estudos de Lucena, Thomé Juca, Soares e Portela (2014), verifica-se que o lodo puro (antes de ser estabilizado para aplicação na pavimentação) é classificado como perigoso em consideração aos níveis de manganês $(\mathrm{Mn}=0,32 \mathrm{mg} / \mathrm{l})$ mais elevado que o parâmetro do Ministério da Saúde (PORTARIA N ${ }^{\circ} 518,2004$ ) que estabelece $0,1 \mathrm{mg} / \mathrm{l}$ para Mn e Níquel $(\mathrm{Ni}=0,21 \mathrm{mg} / \mathrm{l})$ maior que a referência da Companhia de Tecnologia de Saneamento Ambiental - CETESB (2005) que sugere 0,02mg/l de Ni para solo e água subterrânea no Estado de São Paulo. A

pós estabilização com solo-cimento-lodo, os níveis de $\mathrm{Mg}$ caem para os limites aceitáveis validando o uso desse resíduo para meios alternativos.

As análises realizadas por Delgado (2016) para o lodo puro apresentam valores normais quanto aos elementos estudados no processo de lixiviação (Bário total, Cádmio total, Chumbo Total e Cromo total), porém os estudos de solubilização também mostram quantidades elevadas de $\mathrm{Mn}(\approx 6,498 \mathrm{mg} / \mathrm{l})$ e ainda para Ferro total $(\approx 0,632 \mathrm{mg} / \mathrm{l})$ acima do estabelecido pela ABNT (2004) - 0,1mg/l para Mn e 0,3mg/l para Fe.

Neste contexto, é visível a necessidade de estabilização do lodo com algum tipo de aditivo que permita a relação estabilização/solidificação como o cimento usado por Lucena, Thomé Juca, Soares e Portela (2014). Estudo semelhante desenvolvido por Alves (2019) mostra que os níveis $\mathrm{Fe}=40,35 \mathrm{mg} / \mathrm{l}$ para lixiviação, $\mathrm{Mn}=179,72 \mathrm{mg} / \mathrm{l}$ e $\mathrm{Al}=38 \mathrm{mg} / \mathrm{l}$ para solubilização; ultrapassando as especificações das normas já citadas.

São encontrados Mn acima do sugerido pela Norma em questão, para solubilização também na pesquisa Costa (2011) com valor de 43,457mg/l, além de Cádmio com 0,027mg/l e Chumbo com 0,21mg/l. Desse modo, podem-se inferir que um dos principais metais 
presentes no lodo de ETA é o manganês. Os limites para lixiviação e solubilização estão apresentados no Quadro 3.

Quadro 3: Limites sugeridos em norma para lixiviação e solubilização.

\begin{tabular}{|c|c|c|c|c|c|c|}
\hline Metal & Mn & Al & Fe & Pb & Cd & Ni \\
\hline Valor limite lixiviação(mg/l) & $0,1^{\mathbf{1}}$ & --- & $0,3^{2}$ & $1^{3}$ & $0,5^{3}$ & $0,02^{2}$ \\
\hline Valor limite solubilização(mg/l) & $0,1^{\mathbf{3}}$ & $0,2^{\mathbf{3}}$ & $0,3^{3}$ & $0,01^{\mathbf{3}}$ & $0,005^{3}$ & ---- \\
\hline
\end{tabular}

Fonte: Portaria $\mathrm{N}^{\circ} 518(2004)^{1}$, CETESB (2005)² e ABNT (2004) ${ }^{3}$.

O Quadro 3 apresenta os limites para lixiviação e solubilização para o manganês (Mn), alumínio $(\mathrm{Al})$, Ferro $(\mathrm{Fe})$, chumbo $(\mathrm{Pb})$, cádmio $(\mathrm{Cd})$ e para o níquel $(\mathrm{Ni})$ sugeridos pela Portaria $\mathrm{N}^{\circ} 518$ (2004), CETESB (2005) e ABNT (2004).

\section{Considerações Finais}

O presente artigo apresentou formas alternativas para o uso de lodo em pavimentação rodoviária através das literaturas abordadas, onde é possível perceber a importância de uma destinação ambientalmente sustentável para esse resíduo. Além disso, foi possível mensurar os principais metais presentes em teste de lixiviação e solubilização dos lodos estudados bem como sua possibilidade estabilização com material adequado para emprego na construção de rodovias.

Nos estudos quanto aos agregados utilizados percebe-se o maior emprego de cimento, cal hidratada e solo; que misturados ao lodo proporcionam maior estabilização e empregabilidade. Outra forma de aplicação adotada é o uso do lodo calcinado em altas temperaturas para misturas de concreto betuminoso ou misturados a estabilizantes de aplicação direta em base e/ou sub-base de pavimentos. Neste contexto, o resíduo de ETA tem potencial para uso nas camadas de base, sub-base e subleito de pavimentos, agregado em concretos para a recomposição de calçadas e concretos betuminoso.

No que se refere aos processos de lixiviação e solubilização dos metais encontrados nas literaturas, verifica-se a maior presença de Mn em todos os estudos que contemplam esse teste, seguido de $\mathrm{Fe}, \mathrm{Al}, \mathrm{Cd}, \mathrm{Pb}$ e $\mathrm{Ni}$. Estudos descritos mostram que é possível estabilizar os altos níveis de Mn com as misturas de Solo-cimento, passando sua classificação de material 
perigoso para inerte. Desse modo, a presença de metais pesados nos lodos pode ser reduzida quando aplicado o estabilizante adequado.

Recomendam-se estudos futuros com abordagens mais amplas sobre estabilização dos lodos de ETA com material natural e ainda resíduos de telha, cerâmica e tijolos. Pode ser considerada a busca de matérias que confiram maior resistência quando usado o lodo em processos construtivos, visto que esse foi um dos problemas recorrentes nas referências. $\mathrm{O}$ resíduo de ETA tem potencial para uso não só na engenharia de estradas, como também no setor da construção civil em geral e aplicabilidade fins agrícolas que podem ser bons campos de pesquisa.

\section{Referências}

ABNT. (2004). 10005: Procedimento para Obtenção de Extrato lixiviado de Resíduos Sólidos. Associação Brasileira de Normas Técnicas, São Paulo-SP.

Achon C. L, Barroso M. M \& Cordeiro J. S. (2013). Resíduos de estações de tratamento de água e a ISO 24512: desafio do saneamento brasileiro. Engenharia Sanitária e Ambiental, $18(2), 115-22$.

Alves H. D. C. (2019). Análise laboratorial de lodos desidratados de estações de tratamento de água da região metropolitana de Belo Horizonte-MG para uso em pavimentação. (Dissertação de Mestrado, Universidade Federal de Ouro Preto).

Andreoli C \& Pinto M. (2001). Aproveitamento do lodo gerado em estações de tratamento de água e esgotos sanitários, inclusive com a utilização de técnicas consorciadas com resíduos sólidos urbanos. 273p. Projeto PROSAB. Rio de Janeiro: ABES.

Brasil. (2010). Lei no 12.305, de 2 de agosto de 2010. Diário Oficial da União.

Brasil. (2011). Portaria $n^{o} 2.914$, de 12 de dezembro de 2011. Dispõe sobre os procedimentos de controle e de vigilância da qualidade da água para consumo humano e seu padrão de potabilidade. Ministério da Saúde. Diário Oficial da União, (12). 
CETESB. (2005). Decisão de diretoria $N^{o}$ 195-2005- E, de 23 de novembro de 2005. Acesso em 14 janeiro, em https://www.ministeriodesalud.go.cr/gestores_en_salud/pozoAB1089/tabela_valores_2005.pdf.

Coelho, R. V., Tahira, F. S., Fernandes, F., Fontenele, H. B., \& Teixeira, R. S. (2015). Uso de lodo de estação de tratamento de água na pavimentação rodoviária. REEC-Revista Eletrônica de Engenharia Civil, 10(2).

Costa, Á. J. C. D. (2011). Análise de viabilidade da utilização de lodo de ETA coagulado com cloreto de polialumínio (PAC) composto com areia como agregado miúdo em concreto para recomposição de calçadas: estudo de caso na ETA do município de Mirassol-SP (Doctoral dissertation, Universidade de São Paulo - USP).

Delgado, J. (2016). Avaliação da aplicação do lodo da ETA Guandu na pavimentação como disposição final ambientalmente adequada. (Dissertação de Mestrado, Universidade Federal do Rio de Janeiro).

DNER-ME 201. (1994). Solo - Cimento - compressão axial de corpos-de-prova cilíndrico. Acesso em 18 fevereiro, em http://www1.dnit.gov.br/arquivos_internet/ipr/ipr_ new/normas/DNER-ME201-94.pdf.

DNIT 143. (2010). Pavimentação - Base de solo-cimento - Especificação de serviço. Acesso em 18 fevereiro, em ipr.dnit.gov.br/normas-e-manuais/normas/especificacao-de-servicoses/dnit143_2010_es.pdf.

Fernandez, L. P., \& Mikowski, P. C. B. (2016). Avaliação da viabilidade da utilização de lodo de estação de tratamento de água em peças de concreto para pavimentação intertravada (Bachelor's thesis, Universidade Tecnológica Federal do Paraná).

Geyer, A. (2001). Contribuição ao estudo da disposição final e aproveitamento da cinza de lodo de estações de tratamento de esgotos sanitários como adição ao concreto. (Doctoral dissertation, Tese (Doutorado) - Programa de Pós-Graduação em Engenharia CivilUniversidade Federal do Rio Grande do Sul). 
Godoy, L. C. (2013). A logística na destinação do lodo de esgoto. Revista Científica on-lineTecnologia, Gestão e Humanismo, 2(1).

Hoppen, C., Portella, KF., Joukoski, A., Trindade, E. M., \& Andreóli, C. V. (2006). Uso de lodo de estação de tratamento de água centrifugado em matriz de concreto de cimento portland para reduzir o impacto ambiental. Química Nova, 29(1), 79-84.

Iwaki, G. (2018). Destinação Final de Lodos de ETAs e ETEs. Acesso em 18 fevereiro, em https://www.tratamentodeagua.com.br/artigo/destinacao-final-de-lodos-de-etas-e-etes/.

Kawamura, S. (2000). Integrated design and operation of water treatment facilities. John Wiley \& Sons.

Klein, D., \& Oliveira, D. M. (2019). II-542 - Resíduos de Estação de Tratamento de Água e Esgoto: Um estudo de viabilidade para uso na pavimentação no município de Vila Velha/ES. In: $30^{\circ}$ Congresso Brasileiro de Engenharia Sanitária e Ambiental, p. 1-7.

Lucena, L. C. F, Thomé Juca, J. F., Soares, J. B., \& Portela, M. G. (2014). Potential uses of sewage sludge in highway construction. Journal of materials in civil engineering, 26(9), 04014051.

Martinez, J. G. B. (2014). Avaliação de desempenho de misturas betuminosas com adição de lodos de ETA e de ETE. (Dissertação de Mestrado. Universidade Federal de Brasília).

Monteiro, N. B. (2014). Características de lodos de estações de tratamento de água desidratados por sistema geotêxtil: estudo de caso (Master's thesis, Universidade Federal de Pernambuco).

NBR, A. (2004). 10.004/2004. Resíduos sólidos, classificação de resíduos. Rio de Janeiro.

ONU. (2019). A ONU e a água. Acesso em 14 janeiro, em https://nacoesunidas.org/acao/agua/. 
Pereira K. L. D. A. (2012). Estabilização de um solo com cimento e cinza de lodo para uso em pavimentos. (Doctoral dissertation, Dissertação (Mestrado em Engenharia Civil), Universidade Federal do Rio Grande do Norte).

Pereira L. A. G \& Lessa S. N. (2011). O processo de planejamento e desenvolvimento do transporte rodoviário no Brasil. Caminhos de Geografia, 12(40).

PORTARIA N ${ }^{\circ}$ 518. (2004). Norma de Qualidade da Água para Consumo Humano. Acesso em 15 janeiro, em bvsms.saude.gov.br/bvs/publicacoes/portaria_518_2004.pdf.

Rangel, M. L. (2005). A influência da urbanização na qualidade da água: Barragem Mãe D’água-Porto Alegre-RS. Anais do X Encontro de Geógrafos da América LatinaUniversidade de São Paulo.

Ribeiro J. W \& Rooke J. M. S. (2010). Saneamento básico e sua relação com o meio ambiente e a saúde pública. Juiz de Fora, MG, 13.

Rodrigues L. P \& Holanda J. N. F. (2013). Influência da incorporação de lodo de estação de tratamento de água (ETA) nas propriedades tecnológicas de tijolos solo-cimento. Cerâmica, 59(352), 551-6.

SABESP. (2019). Tratamento de Água. Acesso em 14 janeiro, em http://site.sabesp.com.br/site/interna/Default.aspx?secaoId=47.

Silva J. (2008). Comportamento de concreto asfáltico tendo lodo da ETA da cidade de Manaus como fíler (Doctoral dissertation, Dissertação de Mestrado, UFAM, Manaus, AM).

Teixeira S. R, Souza S. A, Souza N. R, Aléssio P \& Santos G. T. A. (2006). Efeito da adição de lodo de estação de tratamento de água (ETA) nas propriedades de material cerâmico estrutural. Cerâmica, 52(323), 215-20.

Wolff E. (2008). O uso do lodo de estação de tratamento de água e resíduos da indústria de celulose (dregs, grits e lama de cal) na produção de cerâmica vermelha. (Tese de Doutorado, Universidade Federal de Minas Gerais). 
Research, Society and Development, v. 9, n. 7, e 786974458, 2020

(CC BY 4.0) | ISSN 2525-3409 | DOI: http://dx.doi.org/10.33448/rsd-v9i7.4458

Porcentagem de contribuição de cada autor no manuscrito

Ana Millene dos Santos Silva - 40\%

Eliezio Nascimento Barboza - 40\%

Maria Fernanda da Cruz Silva - 20\% 